\title{
Selective Vapor Phase Doping of Pt Nanoparticles into Phase-Controlled Nanoalloys
}

\section{-- Supporting Information --}

Nithin Poonkottil ${ }^{\dagger}$, Ranjith K. Ramachandran†, Eduardo Solano ${ }^{\nabla}$, Nadadur Veeraraghavan Srinath ${ }^{\ddagger}$, Ji-Yu Feng ${ }^{\dagger}$, Andreas Werbrouck ${ }^{\dagger}$, Michiel Van Daele $^{\dagger}$, Matthias Filez ${ }^{\dagger}$, Matthias M. Minjauw ${ }^{\dagger}$, Hilde Poelman‡, Alessandro Coati $^{\perp}$, Christophe Detavernier ${ }^{\dagger}$ and Jolien Dendooven*†

+ Conformal Coating of Nanostructures (CoCooN), Department of Solid State Sciences, Ghent University, Krijgslaan 281 (S1), 9000 Ghent, Belgium

\# Laboratory for Chemical Technology, Ghent University, Technologiepark 125, B-9052 Zwijnaarde, Ghent, Belgium

$\perp$ Synchrotron SOLEIL, SixS Beamline, L'Orme des Merisiers, Saint-Aubin, BP48, 91192 Gifsur-Yvette, France

$\nabla$ ALBA Synchrotron Light Source, NCD-SWEET beamline, Carrer de la Llum, 2-26, 08290, Cerdanyola del Vallès, Spain

E-mail: Jolien.Dendooven@Ugent.be 


\section{Composition determination}

To determine the equivalent thickness of the Pt nanoparticle samples and calculate the composition of the Pt-Sn bimetallic nanoparticles, a calibrated X-ray fluorescence (XRF) method was employed as reported before ${ }^{1}$. For the construction of the XRF calibration curves, a series of pure ALD Pt and $\mathrm{SnO}_{2}$ films with different thicknesses were deposited on a silicon substrate with native oxide. After the deposition, the thickness of each film was measured using X-ray reflectivity (XRR). From the thickness, the specific weight of Pt and $\mathrm{SnO}_{2}$ was calculated assuming the densities of the films equal to bulk Pt and $\mathrm{SnO}_{2}$. On each sample, an XRF measurement was done using an integration time of 100s. The XRF intensity counts (i.e., integration of the Pt $L \alpha$ or $S n$ L $\alpha$ fluorescence signal) and specific weight of Pt and Sn were plotted against the thickness of the films as measured by XRR. This in turn yields a calibration curve which could be used to determine the equivalent thickness of Pt nanoparticles and the composition of the synthesized Pt-Sn nanoparticles (Figure S1)
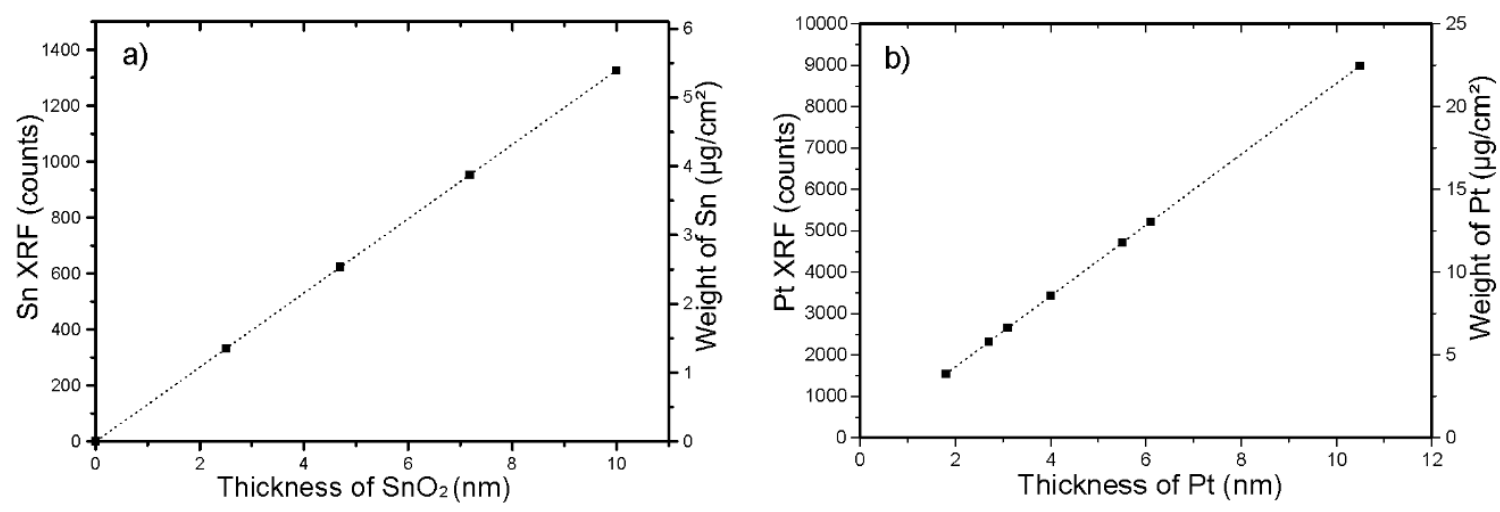

Figure S1. Variation of Sn (a) and Pt (b) L $\alpha$ XRF counts (left y-axis) and weight (right yaxis) against the $\mathrm{Pt}$ and $\mathrm{SnO}_{2}$ film thickness. 


\section{Composition as a function of temperature}

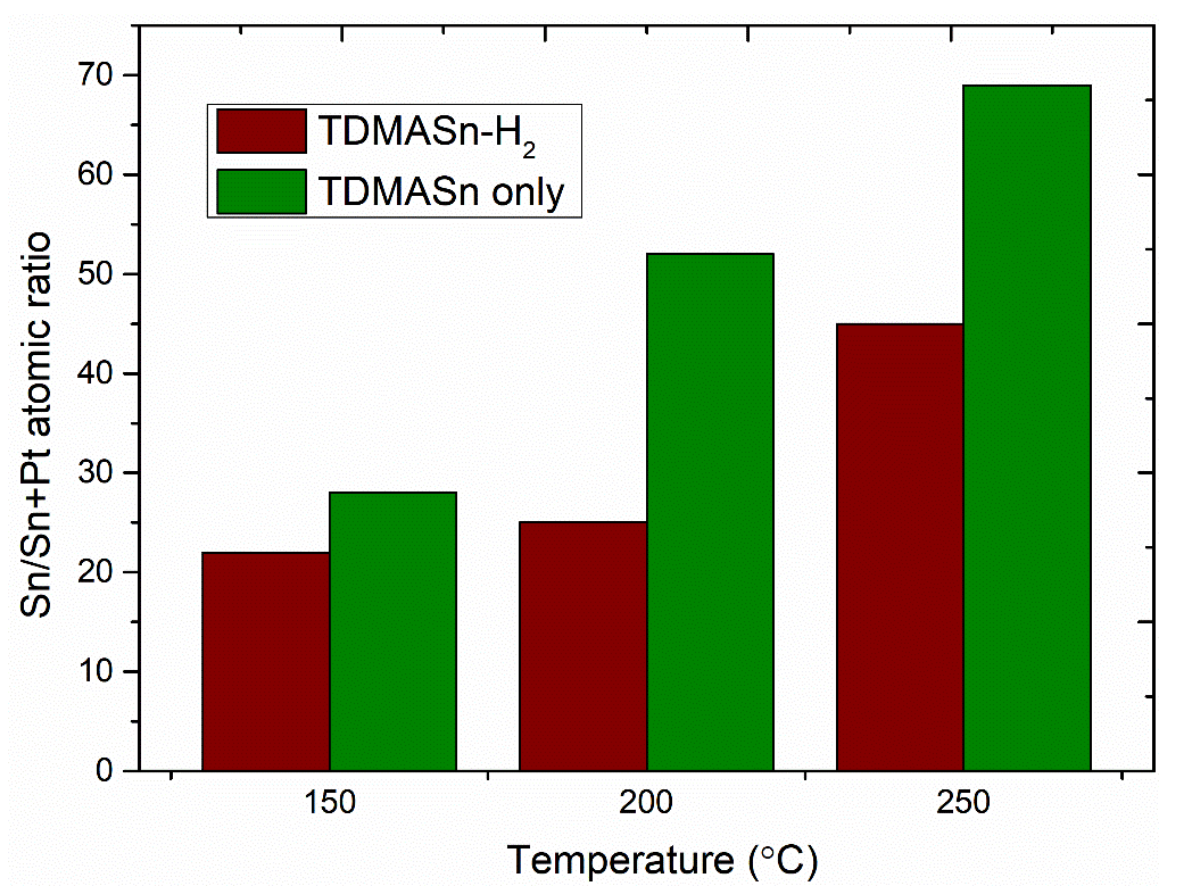

Figure S2: $\mathrm{Sn} / \mathrm{Sn}+\mathrm{Pt}$ atomic ratio for the TDMASn only and TDMASn- $\mathrm{H}_{2}$ process. The TDMASn only process led to higher $\mathrm{Sn} / \mathrm{Sn}+\mathrm{Pt}$ atomic ratio compared to the TDMASn- $\mathrm{H}_{2}$ process, irrespective of the substrate temperature as stated in the main text. 


\section{In situ GISAXS patterns during TDMASn-H2 process}
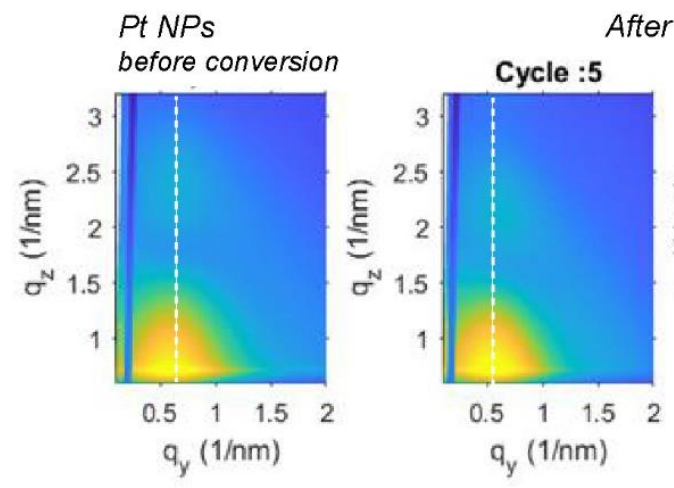

After TDMASn- $\mathrm{H}_{2}$ doping process
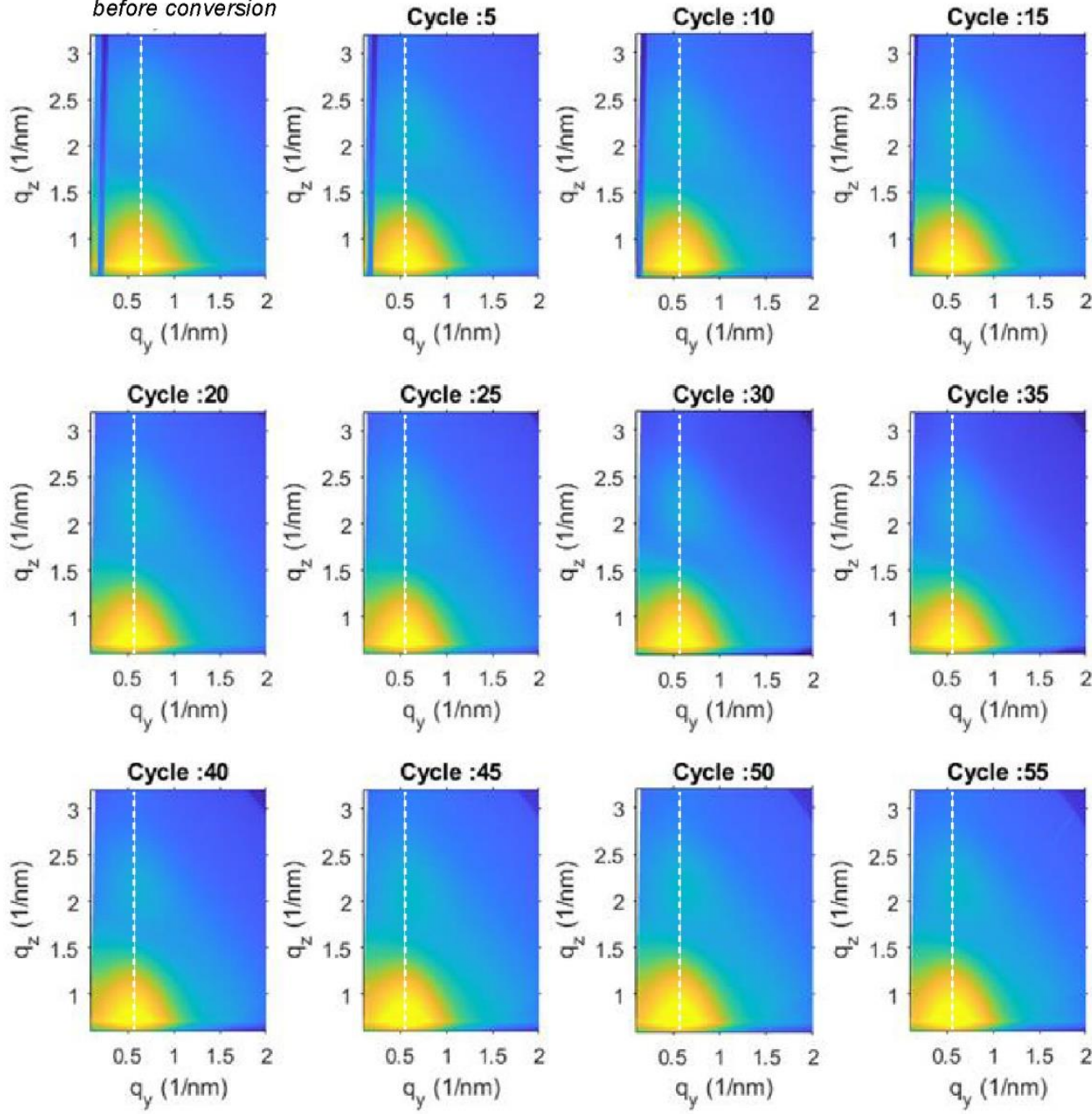

Figure S3. In situ GISAXS data during the TDMASn- $\mathrm{H}_{2}$ process at $200{ }^{\circ} \mathrm{C}$ on ALD prepared Pt NPs (equivalent thickness of $3 \mathrm{~nm}$ ). The first image shows the GISAXS pattern of the Pt NPs before doping and the rest shows the GISAXS images recorded after the TDMASn- $\mathrm{H}_{2}$ doping cycles (the dashed vertical lines indicate the $q_{y \text {,max }}$ position). The images prove that a stable morphology is achieved after 5 doping cycles, in support of Figure 4 in the main manuscript. 


\section{GISAXS data analysis}

In order to extract the real space parameters such as the nanoparticle shape, size, and areal density from the q-space scattering data, we adopted an analysis approach, based on a geometrical model. ${ }^{2}$ IsGISAXS ${ }^{3}$ software was used to calculate the simulated 2D GISAXS patterns, using the extracted morphological parameters as input for the simulation. Then the measured data was compared to the simulated data to validate the proposed strategy. The best agreement between simulation and data was obtained when two particle shapes, full spheroids and hemispheroids are taken in a 1:1 ratio, where both particle geometries were described by the same particle height and radius. The particle radius was described by a lognormal distribution function, and a geometrical standard deviation s, was used to describe the distribution width. Assuming a Gaussian distribution for the particle aspect ratio (height/radius), a joint distribution for the particle height was implemented in IsGISAXS. The distribution width was then described by 0.05 times the central particle aspect ratio value. The distorted wave Born approximation (DWBA) was used to calculate the form factor, the perturbations caused by densely packed particles on a surface was described by the model of the graded interface. ${ }^{4}$ The local monodisperse approximation (LMA) formalism, which is commonly used for polydispersed systems, was also used for the calculations,. The structure factor was calculated using a 1D paracrystal model, which is a regular 1D lattice with loss of long-range order. The distribution of the center-to-center distance $\mathrm{D}$, was described by a Gaussian function with disorder parameter $\omega$, calculated as $\omega=0.4$ D. ${ }^{2}$ 


\section{GISAXS simulations}
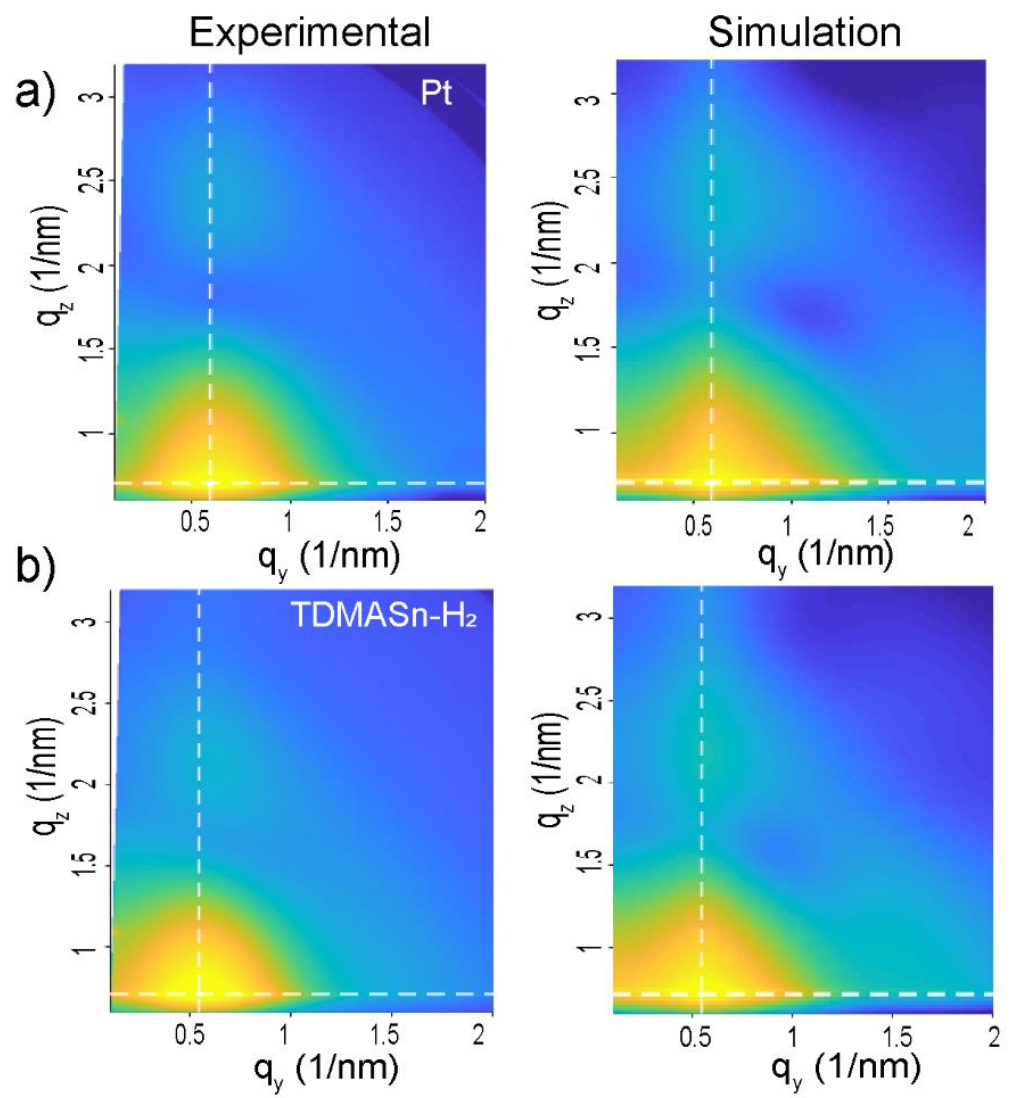

Figure S4. a) and b) Experimental (left) and simulated (right) GISAXS patterns of Pt nanoparticles (equivalent thickness of $3 \mathrm{~nm}$ ) and after TDMASn- $\mathrm{H}_{2}$ treatment, respectively (the dashed vertical lines indicate the $q_{y \text {,max }}$ position). Note that the experimental GISAXS patterns shown here are the same as those shown in Figure 4 in the main text. The table indicates the parameters derived from the GISAXS simulation results. The given errors are based on our previous work ${ }^{5}$ where an average error of $15 \%$ was derived for the GISAXS analysis of the particle center-to-center distance and width, and an error of $7 \%$ on the particle height of $\mathrm{Pt}$ nanoparticles grown with the $\mathrm{MeCpPtMe} / \mathrm{O}_{2}$ process. 
Table S1. Morphological parameters obtained after the GISAXS simulations.

\begin{tabular}{|l|l|l|l|}
\hline & $\begin{array}{l}\text { Interparticle } \\
\text { distance }(\mathbf{n m})\end{array}$ & Height (nm) & Width (nm) \\
\hline Pt NPs & $8.5 \pm 1.3$ & $4.5 \pm 0.3$ & $5.0 \pm 0.8$ \\
\hline After TDMASn- ${ }_{2}$ & $8.9 \pm 1.3$ & $5.0 \pm 0.4$ & $6.2 \pm 0.9$ \\
\hline
\end{tabular}

\section{Doping of WI Pt - Proof of concept}

Table S2. BET surface area of wet impregnated (WI) Pt NPs

\begin{tabular}{|c|c|c|c|}
\hline Sample & BET $\left(\mathbf{m}^{\mathbf{2}} / \mathbf{g}\right)$ & $\begin{array}{c}\text { Average pore } \\
\text { diameter }(\AA)\end{array}$ & $\begin{array}{c}\text { Pore volume } \\
\left(\mathbf{c m}^{3} / \mathbf{g}\right)\end{array}$ \\
\hline $\mathrm{SiO}_{2}$ & $464.3 \pm 5.2$ & $61.0 \pm 0.67$ & $0.71 \pm 0.01$ \\
\hline $\mathrm{Pt} / \mathrm{SiO}_{2}$ & $375.7 \pm 1.2$ & $65.5 \pm 0.60$ & $0.62 \pm 0.0022$ \\
\hline
\end{tabular}

The results are as expected with the BET surface area being lower for the impregnated Pt samples as the $\mathrm{Pt}$ is expected to block some pores and prevent $\mathrm{N}_{2}$ adsorption. This is reflected in the total pore volume obtained whereby it is lower for the Pt impregnated sample.

The TDMASn- $\mathrm{H}_{2}$ treatment was also performed on a WI Pt at substrate temperatures of $200{ }^{\circ} \mathrm{C}$ and $250^{\circ} \mathrm{C}$ TEM/EDX images of these samples were taken after a redox treatment up to $600^{\circ} \mathrm{C}$. From the EDX mapping (Figure S5f and S6f), it is quite clear that there is less Sn than Pt on the NPs prepared at deposition temperature $200^{\circ} \mathrm{C}$ compared to the one at $250{ }^{\circ} \mathrm{C}$. This is in line with our strategy that the amount of Sn incorporated can be 
controlled by varying the substrate temperature. In other words, there is more Sn on the Pt NPs at $250^{\circ} \mathrm{C}$ deposition temperature compared to the one at $200{ }^{\circ} \mathrm{C}$.

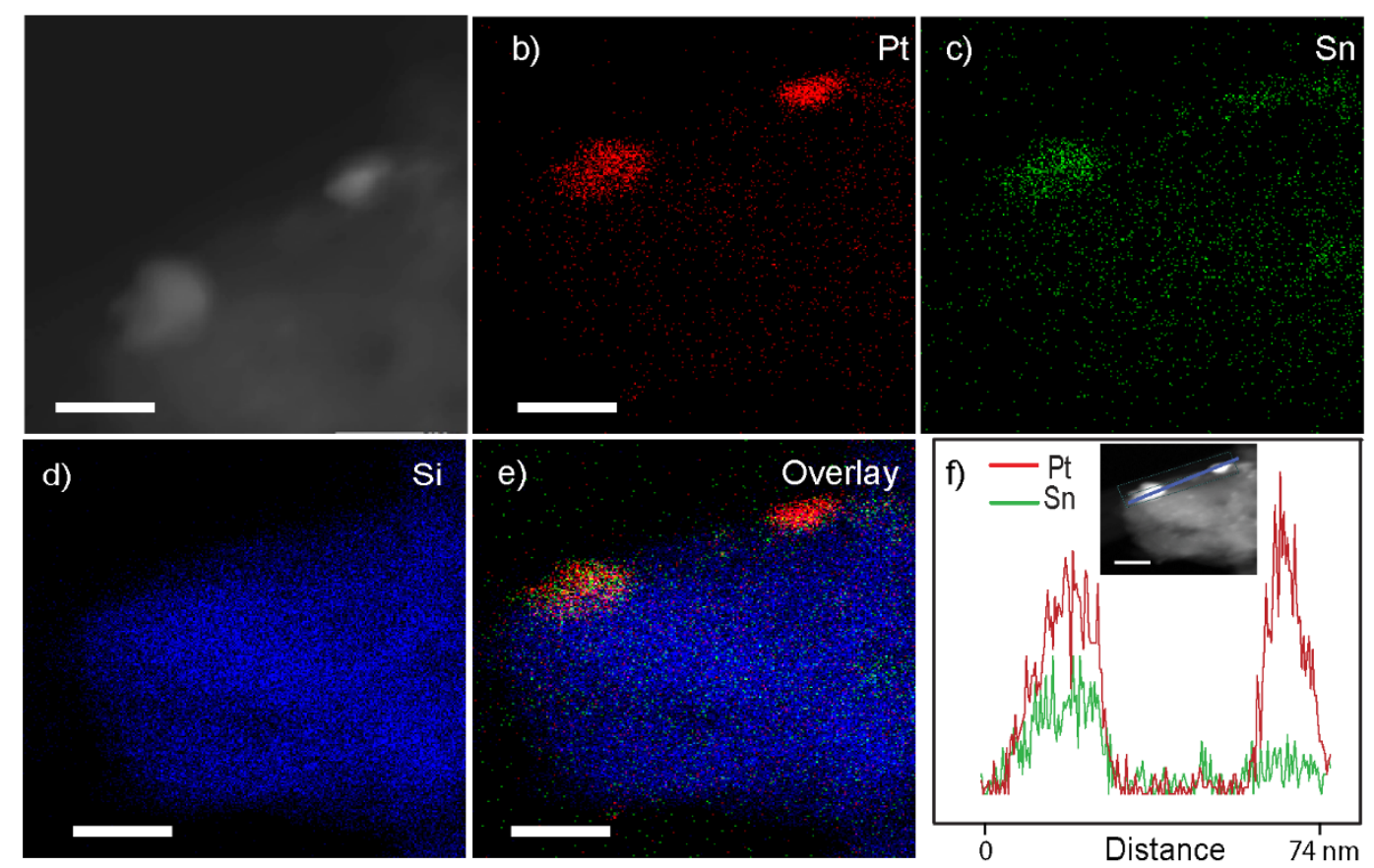

Figure S5: a) STEM image after the $\mathrm{TDMASn}-\mathrm{H}_{2}$ treatment at $200^{\circ} \mathrm{C}$ substrate temperature, followed by a redox treatment at $600^{\circ} \mathrm{C}$. EDX mapping b) Pt c) Sn d) Si e) overlay $(\mathrm{Pt}+\mathrm{Sn}+\mathrm{Si}) \mathbf{f}) \mathrm{EDX}$ line scan, inset shows the region of the scan. All scale bars indicate $100 \mathrm{~nm}$.

Figure S6 (relatively bigger NPs) and S7 (relatively smaller NPs) show that the doping of Sn on WI Pt/SiO2 occurs selectively on the Pt NPs in agreement with the other data presented in the main text of the manuscript. 


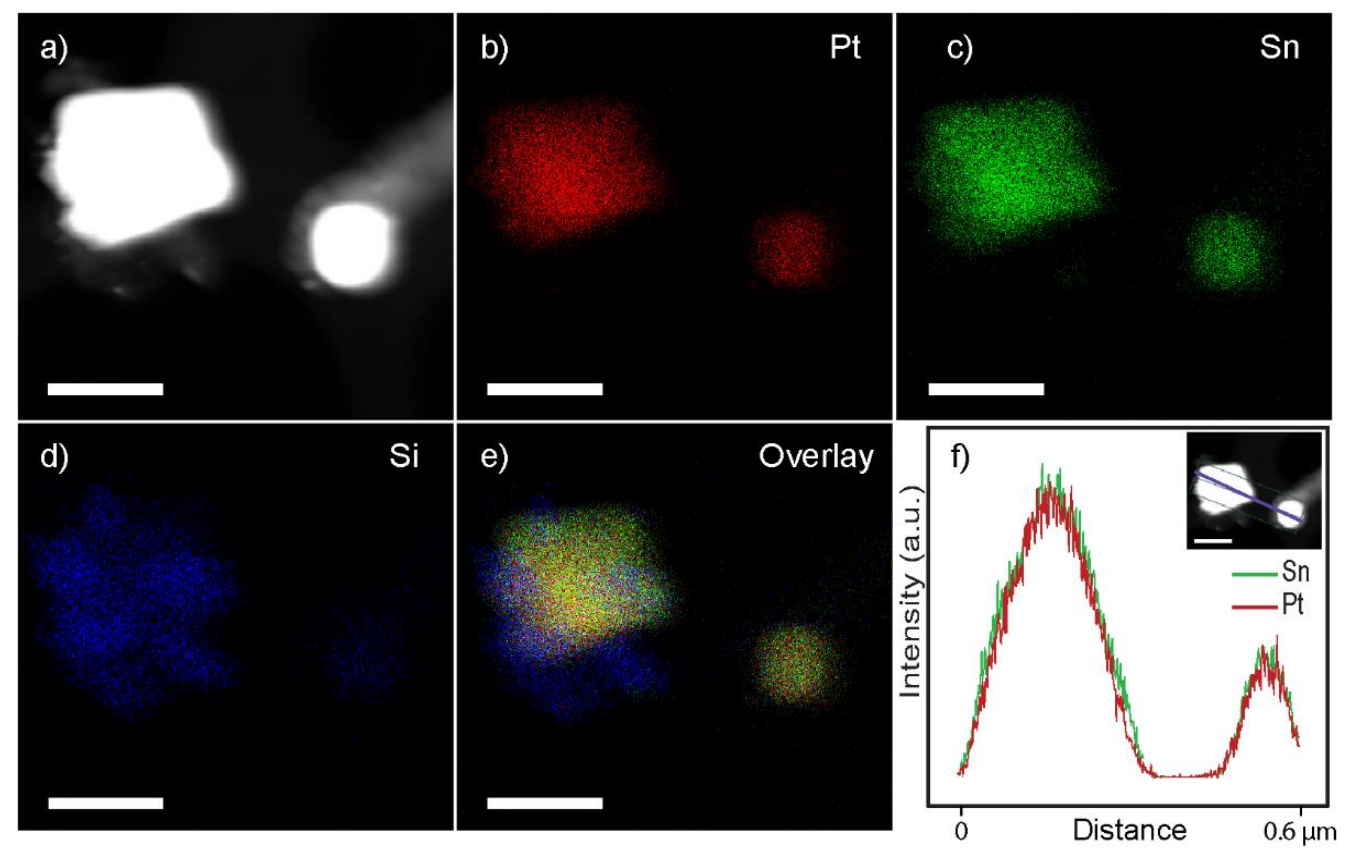

Figure S6. a) STEM image after the TDMASn- $\mathrm{H}_{2}$ treatment on a WI $\mathrm{Pt} / \mathrm{SiO}_{2}$ (powder sample) at $250^{\circ} \mathrm{C}$ substrate temperature, followed by a redox treatment at $600^{\circ} \mathrm{C}$. EDX mapping b) $\mathrm{Pt}$ c) $\mathrm{Sn}$ d) $\mathrm{Si}$ e) overlay (Pt+Sn+Si) f) EDX line scan, inset shows the region of the scan. All scale bars indicate $200 \mathrm{~nm}$.
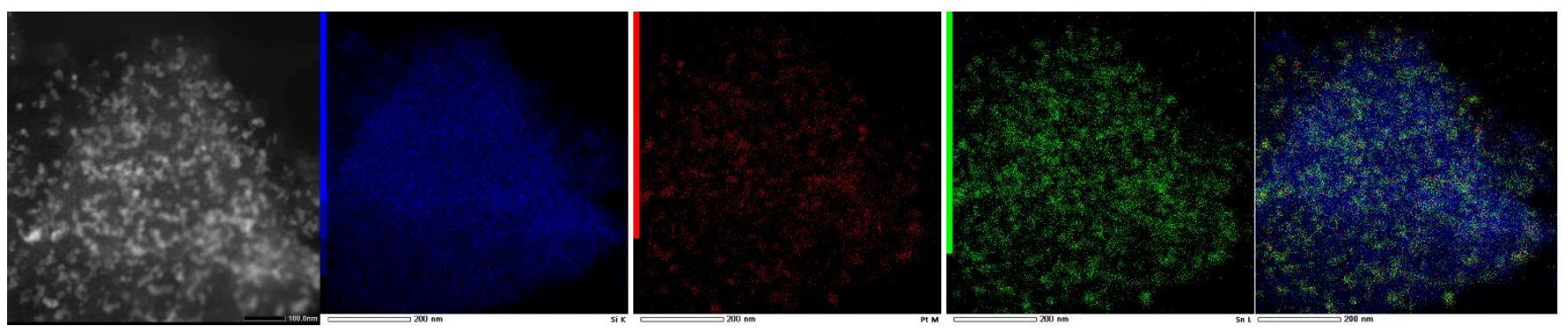

Figure S7: Additional STEM image (first) of the TDMASn-H2 treatment on WI Pt/SiO2 (powder sample at $250^{\circ} \mathrm{C}$ substrate temperature, followed by a redox treatment at $600^{\circ} \mathrm{C}$. EDX mapping of Si, Pt, Sn and overlaid image are followed. 


\section{Preliminary data on the generality of the approach}

a)
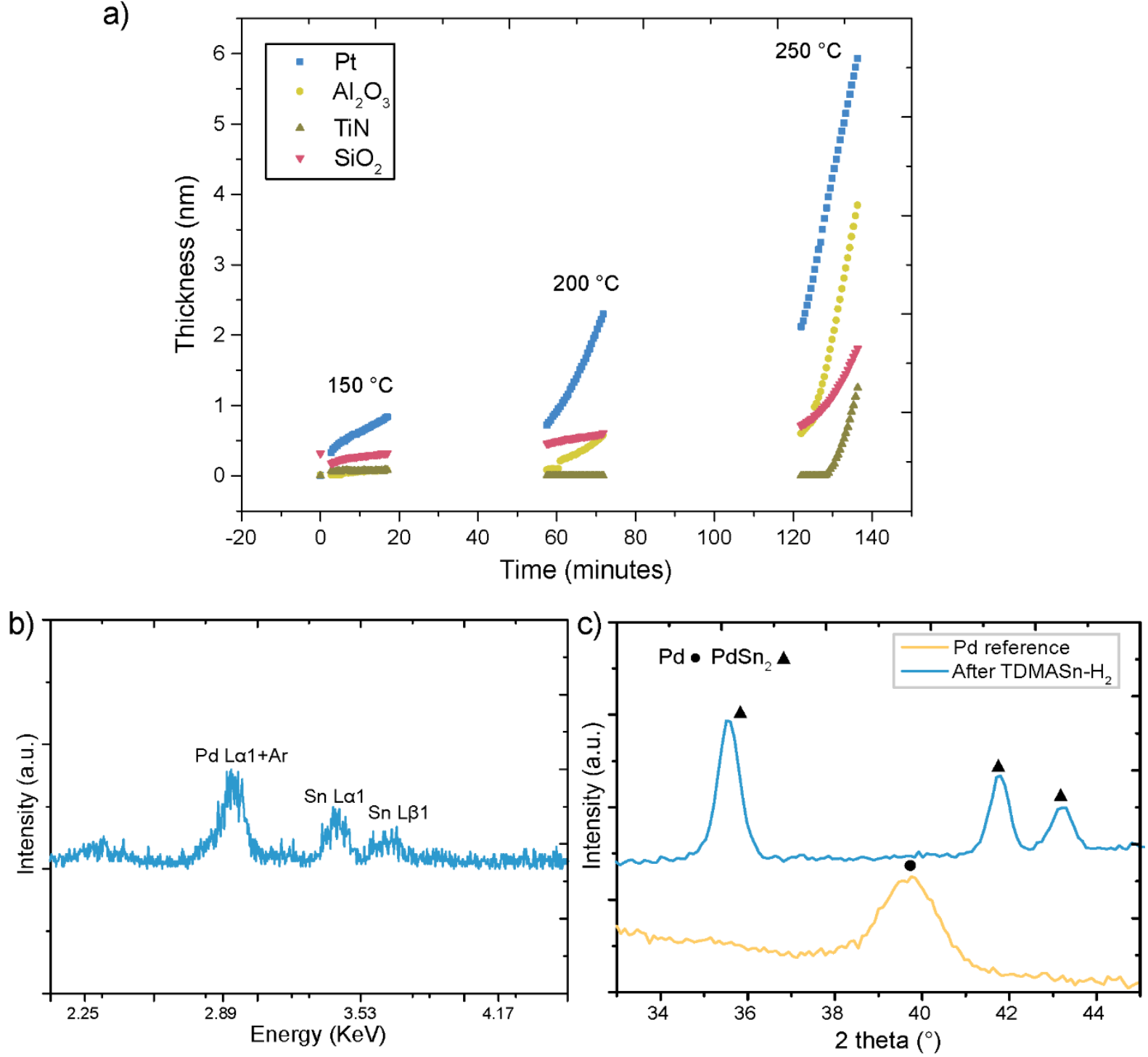

Figure S8: Generality of the selective decomposition and doping strategy. a) Decomposition experiments of TEMAV (a vanadium ALD precursor) on different substrates as obtained by in situ ellipsometry, b) XRF spectrum showing Pd and Sn peaks after the TDMASn-H2 process on $\mathrm{Pd}$ at a substrate temperature of $250^{\circ} \mathrm{C}$ and c) XRD spectra of Pd before and after the TDMASn- $\mathrm{H}_{2}$ treatment 


\section{References}

1. Ramachandran, R. K.; Filez, M.; Dendooven, J.; Galvita, V. V.; Poelman, H.; Solano, E.; Fonda, E.; Marin, G. B.; Detavernier, C., Size-and Composition-Controlled Pt-Sn Bimetallic Nanoparticles Prepared by Atomic Layer Deposition. RSC advances 2017, 7, 20201-20205.

2. $\quad$ Dendooven, J.; Van Daele, M.; Solano, E.; Ramachandran, R. K.; Minjauw, M. M.; Resta, A.; Vlad, A.; Garreau, Y.; Coati, A.; Portale, G., Surface Mobility and Impact of Precursor Dosing During Atomic Layer Deposition of Platinum: In Situ Monitoring of Nucleation and Island Growth. Physical Chemistry Chemical Physics 2020, 22, 2491724933.

3. Lazzari, R., Isgisaxs: A Program for Grazing-Incidence Small-Angle X-Ray Scattering Analysis of Supported Islands. Journal of Applied Crystallography 2002, 35, 406-421.

4. Lazzari, R.; Renaud, G.; Revenant, C.; Jupille, J.; Borensztein, Y., Adhesion of Growing Nanoparticles at a Glance: Surface Differential Reflectivity Spectroscopy and Grazing Incidence Small Angle X-Ray Scattering. Physical Review B 2009, 79, 125428.

5. Dendooven, J.; Ramachandran, R. K.; Solano, E.; Kurttepeli, M.; Geerts, L.; Heremans, G.; Rongé, J.; Minjauw, M. M.; Dobbelaere, T.; Devloo-Casier, K., Independent Tuning of Size and Coverage of Supported Pt Nanoparticles Using Atomic Layer Deposition. Nature communications 2017, 8, 1-12. 